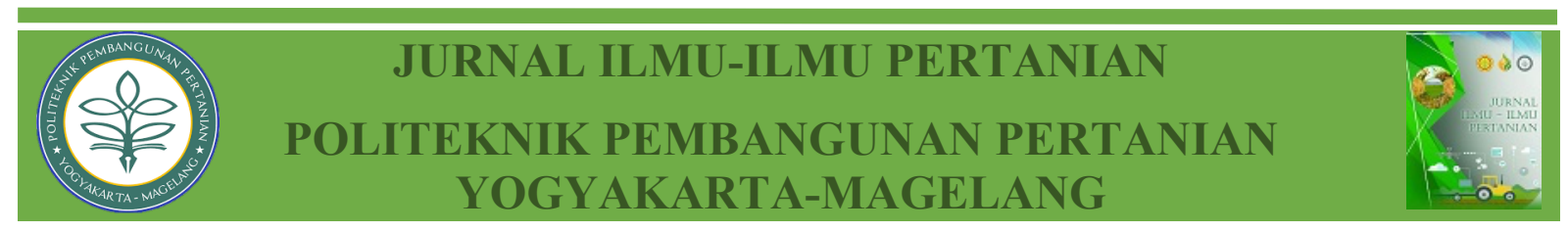

\title{
PENGARUH PEMBENAH TANAH DAN PUPUK HAYATI TERHADAP PENINGKATAN PRODUKTIVITAS JAGUNG HIBRIDA DI KALIMANTAN TIMUR
}

\author{
Tarbiyatul Munawwarah ${ }^{1}$, dan Muh Dimas Arifin ${ }^{1}$ \\ ${ }^{1}$ BPTP Kalimantan Timur, Samarinda, 75117
}

Received

Accepted

Published

Copyright Notice

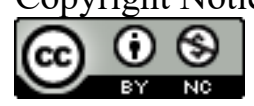

: $\quad$ September $30^{\text {th }}, 2021$

: November $10^{\text {th }}, 2021$

: November $17^{\text {th }}, 2021$

: Authors retain copyright and grant the journal right of first publication with This work is licensed under a Creative Commons Attribution-Non Commercial 4.0 International License.

ABSTRAK: Jagung menjadi komoditas pangan nomor dua setelah padi. Ketersediaan lahan kering yang cukup memadai menjadi alternatif perluasan pengembangan jagung terutama di Kalimantan Timur namun terkendala rendahnya produktivitas lahan kering masam. Tujuan dari kajian ini adalah mengidentifikasi pengaruh kombinasi pembenah tanah dan pupuk hayati untuk meningkatkan produktivitas jagung di lahan kering masam. Kajian budidaya jagung di lahan masam dilaksanakan di Dusun Pulau Mas Desa Buana Jaya, Separi III Kec. Tenggarong Seberang Kab. Kukar pada bulan April - Agustus 2020 dengan menggunakan varietas jagung hibrida Nakula Sadewa 29. Rancangan menggunakan RAK 2 faktor dengan 4 ulangan, yang terdiri atas 5 taraf perbaikan kesuburan tanah $\left(D_{H}=1.000 \mathrm{~kg} \mathrm{kompos} / \mathrm{ha}, 500 \mathrm{~kg}\right.$ dolomit/ha, $10 \mathrm{~kg}$ hayati $/ \mathrm{ha}, 5 \mathrm{~kg} N P K$ mutiara $/ \mathrm{ha} ; D_{N H}=1.000 \mathrm{~kg}$ kompos $/ \mathrm{ha}, 500 \mathrm{~kg}$ dolomit $/ \mathrm{ha}, 5 \mathrm{~kg}$ NPK mutiara/ha; $P_{H}=1.000 \mathrm{~kg}$ kompos $/ \mathrm{ha}, 10 \mathrm{~kg}$ procal $/ \mathrm{ha}, 10 \mathrm{~kg}$ hayati/ha, $5 \mathrm{~kg} \mathrm{NPK}$ mutiara $/ \mathrm{ha} ; P_{N H}=1.000 \mathrm{~kg}$ kompos $/ \mathrm{ha}, 10 \mathrm{~kg} \mathrm{procal} / \mathrm{ha}, 5 \mathrm{~kg} \mathrm{NPK}$ mutiara $/ \mathrm{ha} ; K_{H}=1.000 \mathrm{~kg}$ kompos $/ \mathrm{ha}, 10 \mathrm{~kg}$ hayati/ha, $5 \mathrm{~kg}$ NPK mutiara/ha) dan 2 taraf jarak tanam (tunggal: $70 \times 20$ $\mathrm{cm}$ dan ganda: $80 \times 20 \times 20 \mathrm{~cm}$ ). Hasil menunjukkan bahwa produktivitas tertinggi yaitu 9,5 ton pipilan kering/ha pada perlakuan $P_{H}$ dengan sistem tanam ganda. Pemberian kombinasi pembenah tanah dan pupuk hayati memberikan pengaruh positif terhadap produktivitas jagung di lahan masam.

Kata kunci: lahan masam, jagung NaSa 29, pembenah tanah

ABSTRACT: Maize is the second most important commodity after rice. The existence of dry land, especially in East Kalimantan, is a potential alternative in developing maize cultivation. But it is constrained by the dry land's low fertility. The aim of this study was to identify the effect of soil ameliorant and biofertilizer combination in increasing maize productivity. This study was conducted in Dusun Pulau Mas, Buana Jaya Village, District of Tenggarong Seberang, Kutai Kartanegara Regency during April - August 2020 by using Maize Var. Nakula Sadewa 29. The experiment was designed by using Randomized Block Design (RBD) with two factors and 4 replications, consisted by 5 level of soil amelioration $\left(D_{H}=1000 \mathrm{~kg}\right.$ compost $/ \mathrm{ha}$, $500 \mathrm{~kg}$ dolomite $/ \mathrm{ha}, 10 \mathrm{~kg}$ biofertilizer $/ \mathrm{ha}, 5 \mathrm{~kg} \mathrm{NPK} / \mathrm{ha} ; D_{N H}=1000 \mathrm{~kg}$ compost $/ \mathrm{ha}, 500 \mathrm{~kg}$ 
dolomite/ha, $5 \mathrm{~kg} \mathrm{NPK} / \mathrm{ha} ; P_{H}=1000 \mathrm{~kg}$ compost $/ \mathrm{ha}, 10 \mathrm{~kg}$ procal $/ \mathrm{ha}, 10 \mathrm{~kg}$ biofertilizer $/ \mathrm{ha}, 5$ $\mathrm{kg} \mathrm{NPK} / \mathrm{ha} ; P_{N H}=1000 \mathrm{~kg}$ compost $/ \mathrm{ha}, 10 \mathrm{~kg} \mathrm{procal} / \mathrm{ha}, 5 \mathrm{~kg} \mathrm{NPK} / \mathrm{ha} ; K_{H}=1000 \mathrm{~kg}$ compost/ha, $10 \mathrm{~kg}$ biofertilizer/ha, $5 \mathrm{~kg} \mathrm{NPK} / \mathrm{ha}$ ) and 2 level of planting system (single row: $70 \times 20 \mathrm{~cm}$ and double row: $80 \times 20 \times 20 \mathrm{~cm}$ ). The result shows the highest productivity of 9.5 tons on treatment $P_{H}$ with double planting space. The addition of soil ameliorant and biofertilizer have positive effects in increasing maize productivity in the dry land.

Keywords: acid land, maize NaSa 29, soil ameliorant

\section{PENDAHULUAN}

Ketersediaan lahan kering yang melimpah di Kalimantan Timur sangat berpotensi untuk pengembangan jagung. Pemerintah daerah menyadari hal tersebut salah satunya dengan pencanangan Gerakan Revolusi Jagung di Kabupaten Kutai Kartanegara. Keberlimpahan tersebut terkendala oleh rendahnya kesuburan terutama pada lahan kering masam.

Lahan kering masam adalah lahan yang mempunyai sifat-sifat $\mathrm{pH}$ rendah, kapasitas tukar kation (KTK), kejenuhan basa (KB) dan C-organik rendah, kandungan aluminium (kejenuhan $\mathrm{Al}$ ) tinggi, fiksasi $\mathrm{P}$ tinggi, kandungan besi dan mangan mendekati batas meracuni tanaman, peka erosi, dan miskin unsur biotik (Adiningsih dan Sudjadi, 1993; Soepardi, 2001). Tingginya curah hujan di sebagian wilayah Indonesia menyebabkan tingkat pencucian hara tinggi terutama basa-basa, sehingga basa-basa dalam tanah akan segera tercuci keluar lingkungan tanah dan yang tinggal dalam kompleks adsorpsi liat dan humus adalah ion $\mathrm{H}+$ dan $\mathrm{Al3}+$. Akibatnya tanah menjadi bereaksi masam dengan kejenuhan basa rendah, dan menunjukkan kejenuhan aluminium yang tinggi (Subagyo et al., 2000). Selain itu, tanah-tanah yang terbentuk umumnya merupakan tanah berpenampang dalam, berwarna merahkuning, dan mempunyai kesuburan alami yang rendah

Perbaikan tanah masam dengan pemberian amelioran berupa kapur/dolomit, bahan organik, biochar merupakan perbaikan tanah untuk mereduksi faktor penghambat pertumbuhan tanaman serta meningkatkan ketersediaan hara bagi tanaman. Tanaman jagung, kedelai, kacang tanah dan kacang hijau sangat responsif terhadap kemasaman tanah dan kandungan Al3+ yang tinggi. Oleh karena itu pengelolaan lahan kering masam dengan ameliorasi kapur/dolomit untuk mengurangi kemasaman tanah dan kandungan Al sangat penting dilakukan sebelum pemupukan baik in situ atau kotoran hewan sangat diperlukan agar pemupukan dapat efektif dan efisien (Kasno, 2019).

Dalam studi-studi sebelumnya, pupuk organik diketahui mampu meningkatkan produktivitas pada jagung namun masih digunakan dalam dosis yang tergolong tinggi. Mahmood et al. (2017) dalam studinya menemukan bahwa pupuk organik dari kotoran unggas sebesar 13 ton/ha memiliki efikasi tertinggi dibanding kotoran domba dan kompos. Pangaribuan et al. (2018) melakukan penelitian mengenai kombinasi pupuk organik dan hayati mendapati bahwa kombinasi tersebut memiliki pengaruh positif dalam meningkatkan produktivitas jagung, namun dosis pupuk organik yang digunakan dalam penelitian tersebut juga masih tergolong tinggi yaitu 15 ton per hektar. Penggunaan dosis yang tinggi tersebut meskipun dapat meningkatkan hasil namun dinilai masih kurang ekonomis (Celestina et al., 2019).

Kajian ini dilakukan dengan tujuan mengidentifikasi pengaruh kombinasi pembenah tanah dan pupuk hayati untuk meningkatkan produktivitas jagung di lahan kering masam. 


\section{METODE}

Kajian budidaya jagung di lahan masam dilaksanakan di Dusun Pulau Mas Desa Bhuana Jaya (Separi III) Kec. Tenggarong Seberang Kab. Kutai Kartanegara Prov. Kaltim pada bulan April - Agustus 2020.

Bahan yang digunakan yaitu: satu paket perbaikan kesuburan tanah lahan kering masam (dolomit, procal, kompos kotoran sapi, pupuk hayati, pupuk NPK 16.16.16, NPK mutiara, benih jagung hibrida NaSa 29) dan obat-obatan untuk pengendalian OPT tanaman jagung. Alat yang digunakan yaitu seed planter, cangkul, arit, tali, meteran, dan timbangan digital serta sprayer elektrik.

Desain penelitian menggunakan Rancangan Acak Kelompok (RAK) 2 faktor dengan 4 ulangan. Faktor pertama terdiri atas 5 taraf perbaikan kesuburan tanah, yaitu DH (1.000 kg kompos/ha, 500 $\mathrm{kg}$ dolomit/ha, $10 \mathrm{~kg}$ hayati/ha, $5 \mathrm{~kg}$ NPK mutiara/ha) ; DNH (1.000 kg kompos/ha, $500 \mathrm{~kg}$ dolomit/ha, $5 \mathrm{~kg}$ NPK mutiara/ha); $\mathrm{PH}$ (1.000 kg kompos/ha, $10 \mathrm{~kg}$ procal/ha, $10 \mathrm{~kg}$ hayati/ha, $5 \mathrm{~kg}$ NPK mutiara/ha); PNH $(1.000 \mathrm{~kg}$ kompos/ha, $10 \mathrm{~kg}$ procal/ha, $5 \mathrm{~kg}$ NPK mutiara/ha); KH (1.000 kg kompos/ha, $10 \mathrm{~kg}$ hayati $/ \mathrm{ha}, 5 \mathrm{~kg}$ NPK mutiara/ha). Faktor kedua terdiri dari 2 taraf jarak tanam yaitu T (tunggal: 70×20 $\mathrm{cm}$ ) dan G (ganda: $80 \times 20 \times 20 \mathrm{~cm}$ ).

Perbaikan kesuburan tanah di lahan kering masam spesifik lokasi dilakukan dengan tanpa olah tanah (TOT) atau Minimum Tillage. Penanaman menggunakan seed planter. Teknik pemberian amelioran hanya pada bagian lubang tanam saja dan diberikan sebagai penutup tanah setelah semua bahan dicampur kemudian diperam selama 1 malam terlebih dahulu.

Pemupukan tanaman jagung diberikan pada umur 12-14 hari setelah tanaman tumbuh (HSTb) dengan dosis $350 \mathrm{~kg} / \mathrm{ha}$ (300 kg NPK 16.16.16/ha dan $50 \mathrm{~kg}$ urea/ha) untuk sistem tanam tunggal dan $500 \mathrm{~kg} / \mathrm{ha}$ (400 kg NPK 16.16.16/ha dan
$100 \mathrm{~kg}$ urea/ha) untuk sistem tanam ganda. Pemberian pupuk dengan cara tugal diantara 2 tanaman jagung dalam barisan pada sistem tanam tunggal, sedangkan pada sistem tanam ganda diberikan diantara barisan.

Data penelitian yang dikumpulkan meliputi data primer yaitu tingkat kemasaman tanah $(\mathrm{pH})$ dan data agronomis tanaman (tinggi tanaman; tinggi tongkol; dan produktivitas). Estimasi produktivitas jagung pipilan kering yaitu dengan cara melakukan ubinan jagung tanpa kelobot dengan ukuran $2,5 \mathrm{~m} \times 2,5 \mathrm{~m}$, yang hasilnya dikali 1.600 kemudian dikali faktor konversi 0,5673 (BPS, 2018).

\section{HASIL DAN PEMBAHASAN}

\section{Karakteristik Sumberdaya Lahan dan Iklim di Wilayah Penelitian}

a. Kesuburan tanah

Status kesuburan tanah awal di lokasi penelitian tergolong rendah, hal ini ditunjukkan nilai Kapasitas Tukar Kation (KTK) yang rendah, Kejenuhan Basa (KB) sangat rendah, $\mathrm{P}$ tersedia rendah, $\mathrm{K}$ tersedia rendah dan C-organik sangat rendah (Tabel $1)$.

Umumnya tanah lahan masam memiliki kandungan $\mathrm{P}$ total dan $\mathrm{K}$ total tinggi namun tidak tersedia karena terjerap/teradsorbsi pada koloid tanah. Oleh karena itu, pemberian pupuk hayati pada lahan kering masam sangat dianjurkan. Peran bakteri pelarut fosfat (BPF) dan kalium seperti Bacillus sp, Azotobacter sp, Azospirilium sp, dan Pseudomonas sp yang terkandung dalam pupuk hayati dapat memobilisasi $\mathrm{P}$ dan $\mathrm{K}$ yang tinggi menjadi tersedia bagi tanaman.

Campuran (mix) amelioran yang bersumber dari kompos sapi dan kimia (Procal) serta pupuk hayati dapat meningkatkan derajat keasaman tanah $\mathrm{pH}$. Pengukuran $\mathrm{pH}$ dengan menggunakan $\mathrm{pH}$ tester setelah penelitian menunjukkan peningkatan $\mathrm{pH}$ dari 4,98 menjadi 5,8. Pemberian amelioran (kompos dan Procal) dapat menurunnya kandungan Aluminium 
sehingga terjadi peningkatan $\mathrm{pH}$ yang secara tidak langsung juga mendukung kehidupan mikroba. Menurut Boraste, et al. (2009) dan Panda (2011), Pupuk hayati bukanlah pupuk yang langsung menyediakan hara bagi tanaman. Pupuk hayati mempunyai fungsi ganda yaitu sebagai (a) penambat $\mathrm{N}$, (b) memobilisasi fosfat dan kalium, (c) penghasil fitohormon (PGPR) dan penghasil siderofor, (d) bersimbiosis mutualisme dengan perakaran (mikoriza), dan (e) perombak bahan organik /dekomposer (Simarmata, et al, 2012).

Tabel 1. Sifat fisik dan kimia tanah lahan kering masam di lokasi penelitian.

\begin{tabular}{|c|c|c|c|}
\hline No & Sifat tanah & Nilai & Kriteria \\
\hline \multirow[t]{4}{*}{1} & Tekstur & & Lempung \\
\hline & Pasir & 65,54 & \\
\hline & Debu & 18,55 & \\
\hline & Liat & 15,90 & \\
\hline 2 & $\mathrm{pH} \mathrm{H} 2 \mathrm{O}$ & 4,98 & Masam \\
\hline \multirow[t]{4}{*}{3} & Bahan Organik & & \\
\hline & C-organik & 0,93 & Sangat Rendah \\
\hline & N-total & 0,08 & Rendah \\
\hline & $\mathrm{C} / \mathrm{N}$ & 11,625 & Sedang \\
\hline \multirow[t]{4}{*}{4} & Ekstrak HCL 25\% & & \\
\hline & $\mathrm{P}_{2} \mathrm{O}_{5}$ & 0,91 & Tinggi \\
\hline & $\mathrm{K}_{2} \mathrm{O}$ & 1,18 & Tinggi \\
\hline & $\mathrm{P}_{2} \mathrm{O}_{5}$ Bray I & 12,11 & Rendah \\
\hline \multirow[t]{8}{*}{5} & Susunan Kation Basa dan Asam & & \\
\hline & K-tukar ( me/100 ) & 0,03 & Sangat Rendah \\
\hline & Na-tukar (me/100) & 0,33 & Rendah \\
\hline & Mg-tukar (me/100) & 0,03 & Sangat Rendah \\
\hline & Ca-tukar (me/100) & 0,2 & Sangat Rendah \\
\hline & $\mathrm{KTK}(\mathrm{me} / 100)$ & 6,73 & Rendah \\
\hline & $\mathrm{Al}^{3+}$ & 2,73 & \\
\hline & $\mathrm{H}^{+}$ & 1,09 & \\
\hline 6 & Kejenuhan Basa (\%) & 13,38 & Sangat Rendah \\
\hline
\end{tabular}

\section{b. Curah Hujan}

Iklim sangat berpengaruh terhadap pertumbuhan dan produksi tanaman, seperti curah hujan, suhu dan lamanya penyinaran. Curah hujan yang melebihi batas akan mengakibatkan peningkatan volume air pada permukaan tanah sehingga dapat mempengaruhi pertumbuhan tanaman. Curah hujan yang berlebihan akan mempengaruhi produktivitas tanaman yang mengakibatkan pertumbuhan tanaman terganggu. Suhu udara mempengaruhi aktivitas kehidupan tanaman, antara lain pada proses fotosintesis, respirasi, transpirasi, pertumbuhan, penyerbukan, pembuahan, dan keguguran buah. Berikut ini distribusi hujan di Kalimantan Timur pada tahun 2020 bersumber dari BMKG UPT Kota Samarinda yang berada di Temindung (Gambar 1). 


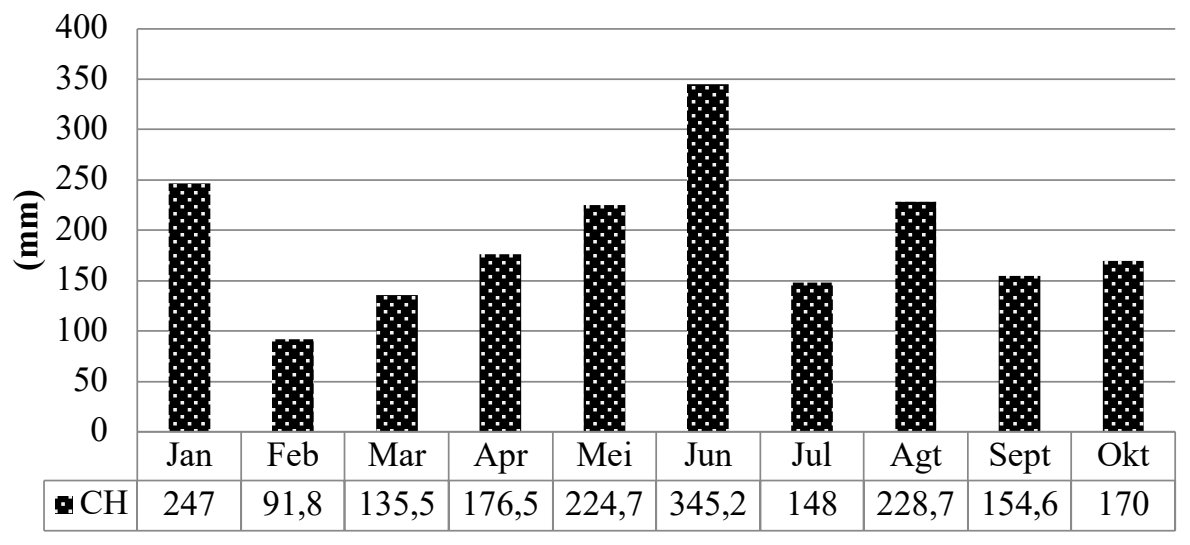

Gambar 1. Rata-rata curah hujan bulanan tahun 2020 di Stasiun BMKG Temindung

Tanaman jagung merupakan tanaman C4 yang perlu penyinaran $70-80 \%$. Sinar matahari diperlukan sebagai sumber energi yang membantu dalam proses fotosintesis. Sehingga tanaman jagung membutuhkan curah hujan relatif sedikit. Tanaman jagung tumbuh normal pada curah hujan sekitar $250-5.000 \mathrm{~mm}$. Curah hujan di luar rentang tersebut akan menurunkan hasil jagung. Kondisi tanah yang jenuh air pada bulan Juni 2020 (saat tanaman berumur 55 HSTb) meningkatkan kelembaban tanah yang menyebabkan pengisian buah tidak maksimal. Tingginya curah hujan juga menyebabkan janten (jagung kedua yang muncul setelah tongkol utama) tidak berkembang padahal persentase jumlah tongkol 2 yaitu $\pm 25,6 \%$ (perlakuan tanam tunggal) dan $10,1 \%$ (perlakuan tanam ganda).

\section{Pengaruh amelioran terhadap keragaan tanaman jagung}

Manajemen kesuburan tanah lahan kering masam dengan teknik pencampuran amelioran sintetis dan kompos kotoran sapi yang ditambah pupuk hayati pada penelitian ini menunjukkan bahwa kombinasi ketiga bahan cenderung memberi pengaruh pada tinggi tanaman yakni lebih tinggi dibanding hanya amelioran alami dan pupuk hayati.

Pengaruh faktor perbaikan kesuburan tanah terlihat beda nyata antar jenis amelioran sintetis (Dolomit dan Procal). Perlakuan PH (1.000 kg kompos kotoran sapi+10 $\quad \mathrm{kg}$ Procal+10 $\mathrm{kg}$ Kayabio) menunjukkan keragaan tinggi tanaman pada akhir kegiatan (umur $90 \mathrm{HSTb}$ ) paling tinggi. Demikian pula adanya penambahan pupuk hayati menunjukkan peningkatan lebih tinggi dibanding amelioran saja (Tabel 2).

Sedangkan pengaruh teknik budidaya (sistem/jarak tanam) antara tunggal dan ganda tidak beda nyata (Tabel 2). Hal ini diduga karena pemberian pupuk kimia telah cukup mecukupi kebutuhan tanaman. Dosis $350 \mathrm{~kg} / \mathrm{ha}$ (300 kg NPK 16.16.16/ha dan $50 \mathrm{~kg}$ urea/ha) untuk sistem tanam tunggal dan $500 \mathrm{~kg} / \mathrm{ha} \quad(400 \mathrm{~kg}$ NPK 16.16.16/ha dan $100 \mathrm{~kg}$ urea/ha) untuk sistem tanam ganda.

Tabel 2. Pengaruh faktor pemberian amelioran terhadap tinggi tanaman NaSa 29.

\begin{tabular}{lcc}
\hline Perlakuan & Tinggi Tanaman (cm) \\
\hline$D_{\mathrm{H}}$ Kompos+Dolomit+Hayati & $242,17{ }^{\mathrm{ab}}$ \\
$\mathrm{D}_{\mathrm{NH}}$ Kompos+Dolomit & $241,52 \mathrm{ab}^{\mathrm{ab}}$ \\
$\mathrm{P}_{\mathrm{H}}$ Kompos+Procal+Hayati & $249,33 \mathrm{c}^{\mathrm{c}}$ \\
$\mathrm{P}_{\mathrm{NH}}$ Kompos+Procal & $242,25 \mathrm{ab}^{\mathrm{ab}}$ \\
$\mathrm{K}_{\mathrm{H}}$ Kompos+Hayati & $232,02{ }^{\mathrm{a}}$ \\
\hline
\end{tabular}

Ket : angka yang diikuti huruf yang sama menunjukkan tidak beda nyata uji DMRT 5\% 
tanah dan teknik budidaya jagung (sistem tanam) sangat bervariasi, namun secara umum pengaruh pemberian Procal dengan sistem ganda cenderung paling tinggi dibanding kombinasi lainnya (Tabel 3). Hal ini disebabkan kondisi iklim bulan Juni 2020 terjadi banjir di sebagian wilayah di
Kalimantan Timur tidak terkecuali lokasi penelitian di lahan petani. Sehingga layout petak perlakuan yang berada pada posisi agak rendah terkena limpasan air permukaan terutama perlakuan $\mathrm{PH}$ dengan sistem tanam tunggal.

Tabel 3. Pengaruh interaksi amelioran dan sistem tanam terhadap tinggi tanaman NaSa 29.

\begin{tabular}{|c|c|c|c|c|c|}
\hline \multirow{2}{*}{$\begin{array}{c}\begin{array}{c}\text { Perlakuan } \\
\text { Tunggal }\end{array} \\
\mathrm{D}_{\mathrm{H}}\end{array}$} & \multicolumn{2}{|c|}{$\begin{array}{c}\text { Tinggi } \\
\operatorname{tanaman}(\mathbf{c m})\end{array}$} & \multirow{2}{*}{$\begin{array}{c}\begin{array}{c}\text { Perlakuan } \\
\text { Ganda }\end{array} \\
\mathrm{D}_{\mathrm{H}}\end{array}$} & \multicolumn{2}{|c|}{$\begin{array}{c}\text { Tinggi } \\
\operatorname{tanaman}(\mathrm{cm})\end{array}$} \\
\hline & 264,05 & $\mathrm{e}$ & & 231,23 & $\mathrm{ab}$ \\
\hline $\mathrm{D}_{\mathrm{NH}}$ & 238,40 & $a b c$ & $\mathrm{D}_{\mathrm{NH}}$ & 243,08 & bed \\
\hline $\mathrm{P}_{\mathrm{H}}$ & 222,70 & a & $\mathrm{P}_{\mathrm{H}}$ & 252,03 & cde \\
\hline $\mathrm{P}_{\mathrm{NH}}$ & 259,05 & de & $\mathrm{P}_{\mathrm{NH}}$ & 244,48 & bcd \\
\hline $\mathrm{K}_{\mathrm{H}}$ & 234,30 & $\mathrm{ab}$ & $\mathrm{K}_{\mathrm{H}}$ & 230,88 & $\mathrm{ab}$ \\
\hline
\end{tabular}

Ket : angka yang diikuti huruf yang sama menunjukkan tidak beda nyata uji DMRT 5\%

\section{Produktivitas jagung Nasa 29 di lahan masam}

Kandungan $\mathrm{P}$ dan $\mathrm{K}$ pada lahan kering masam tinggi namun dalam kondisi tidak tersedia bagi tanaman (Tabel 1). Aktivitas mikroba diperlukan agar unsur $\mathrm{P}$ dan $\mathrm{K}$ menjadi tersedia bagi tanaman, sehingga pemberian pupuk hayati menjadi wajib hukumnya diberikan agar amelioran (sintesis dan alami) dapat maksimal bermanfaat dalam perbaikan kesuburan tanah masam.

Kombinasi tata kelola/manajemen pengelolaan lahan dan teknik budidaya tanaman (peningkatan jumlah populasi tanaman) serta ditunjang input pupuk sesuai dengan kebutuhan tanaman maka produktivitas tanaman akan meningkat pula.

Ubinan dengan ukuran $2,5 \mathrm{~m} \times 2,5 \mathrm{~m}$ dilakukan saat umur tanaman jagung 105 hari karena telah ditandai kelobot kering dan biji keras. Jumlah populasi ubinan pada sistem tanam tunggal berjumlah 52 tanaman atau 4 baris dengan jumlah tanaman perbaris 13 tanaman, sedang sistem tanam ganda 78 tanaman atau 6 baris dengan jumlah tanaman perbaris sama yaitu 13 tanaman.

Hasil ubinan menunjukkan bahwa bobot tongkol panen tertinggi pada perlakuan kombinasi $1.000 \mathrm{~kg}$ kompos kotoran sapi, $10 \mathrm{~kg}$ procal, dan $10 \mathrm{~kg}$ pupuk hayati. Peningkatan jumlah populasi persatuan luas yang diimbangi dengan pemupukan sesuai kebutuhan tanaman menunjukkan hasil bahwa sistem ganda lebih tinggi dibanding dengan sistem tunggal. Estimasi produktivitas dari hasil ubinan pengaruh amelioran dan pupuk hayati serta sistem tanam dapat dilihat pada Tabel 4. Walaupun hasil yang diperoleh belum mencapai potensi hasil jagung hibrida NaSa 29 berdasarkan deskripsi varietasnya yaitu 13,5 ton/ha, namun rakitan teknologi pada kajian ini telah menunjukkan bahwa produktivitas lahan sub optimal memiliki potensi jika manajemen pengelolaan lahan dilakukan secara tepat dan diimbangi dengan pemberikan input sesuai dengan kebutuhan tanaman. Nilai terendah produktivitas pada perlakuan $\mathrm{DH}$ dengan pertanaman tunggal sebesar 6,11 ton/ha masih lebih tinggi dibanding prodiktivitas rata-rata jagung provinsi Kalimantan Timur di tahun 2017 sebesar 50,81 ku/ha (Kementan, 2019). Perlakuan tanam ganda dengan perlakuan DNH PH dan PNH juga menunjukkan produktivitas yang lebih tinggi dibanding pertanaman jagung $\mathrm{NaSa} 29$ pada pendampingan terdahulu di beberapa 
wilayah pengembangan Kabupaten Kutai Kartanegara yang secara rata-rata 5,45 8,50 ton pipilan kering (Hidayanto, et al., 2018; Munawwarah, 2020). Sebagai perbandingan pula, pertumbuhan varietas jagung NaSa 29 yang ditanam pada lahan masam pada waktu yang sama dengan hanya menggunakan teknologi pemupukan menunjukkan tinggi tanaman tertinggi $\pm 150 \mathrm{~cm}$ dan tinggi tongkol $\pm 50-70 \mathrm{~cm}$

Hal ini membuktikan bahwa manajemen perbaikan lahan kering masam dengan pemberian amelioran dan pupuk hayati memberikan hasil tertinggi dibanding tanpa amelioran sintetis. Jenis amelioran berpengaruh positif meningkatkan hasil, karena bahan baku utama Procal selain mengandung kalsium karbonat (CaCO3) juga bahan lainnya seperti unsur Nitrogen (N), Magnesium $(\mathrm{Mg})$, Sulfur (S), Boron (Bo), dan asam humat. Serta jumlah pemberiannya lebih hemat $15-25 \%$ dibanding kaptan, artinya ada efisiensi baik jumlah maupun biaya.

Tabel 4. Pengaruh ameliorasi dan sistem tanam terhadap produktivitas $\mathrm{NaSa} 29$

\begin{tabular}{llcccc}
\hline \multirow{2}{*}{ Perlakuan } & \multicolumn{2}{c}{ Tunggal } & \multicolumn{2}{c}{ Ganda } \\
\cline { 3 - 6 } & & \multicolumn{3}{c}{ (ton/ha) } \\
\cline { 3 - 5 } & Tongkol & $\begin{array}{c}\text { Pipilan } \\
\text { kering }\end{array}$ & Tongkol & $\begin{array}{c}\text { Pipilan } \\
\text { kering }\end{array}$ \\
\hline $\mathrm{D}_{\mathrm{H}}$ & Kompos+Dolomit+Hayati & 10,78 & 6,11 & 14,32 & 8,12 \\
$\mathrm{DN}_{\mathrm{H}}$ & Kompos+Dolomit & 11,20 & 6,35 & 14,00 & 7,94 \\
$\mathrm{P}_{\mathrm{H}}$ & Kompos+Procal+Hayati & 12,88 & 7,31 & 16,75 & 9,50 \\
$\mathrm{PN}_{\mathrm{H}}$ & Kompos+Procal & 12,00 & 6,81 & 15,28 & 8,67 \\
$\mathrm{~K}_{\mathrm{H}}$ & Kompos+Hayati & 11,84 & 6,72 & 14,21 & 8,06 \\
\hline
\end{tabular}

Sumber : Hasil olah data

\section{SIMPULAN DAN SARAN}

Simpulan dari pengkajian budidaya jagung lahan masam yaitu:

1. Paket teknologi anjuran pengelolaan kesuburan tanah di lahan kering masam untuk peningkatan produksi jagung hibrida yaitu ameliorasi menggunakan bahan sintetis dan alami serta penambahan pupuk hayati yaitu 1.000 kg kompos kotoran sapi, $10 \mathrm{~kg}$ Procal dan $10 \mathrm{~kg}$ pupuk hayati per-hektar yang diberikan pada sekitar lubang tanam.

2. Secara keseluruhan, kombinasi paket teknologi pengelolaan kesuburan tanah dan teknik budidaya jagung (sistem tanam) mengalami peningkatan produktivitas $\pm 20-33 \%$ dengan $\mathrm{B} / \mathrm{C}$ rasio diatas 2 .

Kombinasi paket teknologi pengelolaan kesuburan tanah selanjutnya disebut "Teknologi Ameliorasi Procal Plus" dengan "Teknologi Sistem Tanam Ganda" memberikan produktivitas tertinggi yaitu 9,5 ton pipilan kering/ha. Guna memperbaiki sifat fisik, kimia dan biologi tanah di lahan kering masam dianjurkan menambahkan pembenah tanah dan pupuk hayati dengan teknik pemeraman yang diberikan sebagai penutup lubang tanam karena lebih efisien penggunakan pupuk organik dan kaptan yang selama ini ruwah. Penggunaan alat tanam semi mekanis (seed planter) sangat dianjurkan karena fleksibel pada topografi bergelombang hingga berbukit.

Guna mencapai hasil sesuai potensi varietas jagung hibrida NaSa 29, maka perlu penelitian lanjutan dosis pupuk optimal dengan sistem tanam ganda.

\section{PUSTAKA ACUAN}

Adiningsih J. dan Sudjadi M. (1993). Peranan sistem bertanam lorong (Alley cropping) dalam meningkatkan kesuburan tanah pada lahan kering masam. Proceedings of "Seminars on Soil and Agroclimatic Research". Pusat Penelitian dan Pengembangan Tanah dan Agroklimat Badan Penelitian dan Pengembangan Pertanian Departemen Pertanian.

Boraste A., Vamsi K.K., Jhadav A., 
Khairnar Y., Gupta N., Trivedi S., Patil P., Gupta G., Gupta M., Mujapara A.K., Joshi B. (2009). Biofertilizers: A novel tool for agriculture. Int $J$ Microbiol Res, 1, 23-31. Doi:10.9735/0975-5276.1.2.23-31

BPS. (2018). Peraturan Kepala Badan Pusat Statistik Nomor 56 tahun 2018 tentang Pedoman Pengumpulan Data Survei Ubinan Tanaman Pangan. https://pbd.bps.go.id/hukum/actions/ce tak.php?jenis $=$ P08\&tahun $=2018 \&$ no $\underline{\text { mor }=56}$

BPTP Kaltim. (2018). Laporan Teknis Taman Teknologi Pertanian. Samarinda: BPTP Kalimantan Timur.

BPTP Kaltim. (2020). Laporan Teknis Budidaya Jagung Lahan Masam di Kalimantan Timur. Samarinda: BPTP Kalimantan Timur.

Celestina, C., Hunt, J. R., Sale, P. W. G., \& Franks, A. E. (2019). Attribution of crop yield responses to application of organic amendments: A critical review. Soil and Tillage Research, 186, 135-145. Doi: 10.1016/j.still.2018.10.002

Hidayanto, M. (2018). Laporan Teknis Kajian Teknologi Budidaya Jagung di Taman Teknologi Pertanian Desa Bangun Rejo tahun 2016 - 2017. Samarinda: BPTP Kalimantan Timur.

Kasno, A. (2019). Perbaikan Tanah untuk Meningkatkan Efektivitas dan Efisiensi Pemupukan Berimbang dan Produktivitas Lahan Kering Masam. Jurnal Sumberdaya Lahan, 13, 27-40. Doi:

http://dx.doi.org/10.21082/jsdl.v13n1. 2019.27-40

Kementerian Pertanian. (2019). Statistik Pertanian 2019. http://epublikasi.pertanian.go.id/arsipperstatistikan/713-statistik-pertanian2019

Mahmood F., Khan I., Ashraf U., Shahzad T., Hussain S., Shahid M., Abid M., Ullah S. (2017). Effects of organic and inorganic manures on maize and their residual impact on soil physicochemical properties. J. Soil Sci. Plant Nutr.,17, 22-32. Doi:10.4067/S071895162017005000002

Munawwarah, T. (2020). Laporan Teknis Kajian Teknologi Jagung Lahan Masam di Kalimantan Timur. Samarinda: BPTP Kalimantan Timur.

Panda, H. (2011). Manufacture of Biofertilizer and Organic Farming. New Delhi: Asia Pacific Business Press Inc.

Pangaribuan, D.H., Hendarto K., Elzhivago, S.R., Yulistiani, A. (2018). The effect of organic fertilizer and urea fertilizer on growth, yield and quality of sweet corn and soil health. Asian $J$ Agri \& Biol, 6 (3), 335-344.

Simarmata, T., Joy, B., Danapriatna, N. (2012). Peranan Penelitian dan Pengembangan pada Industri Pupuk Hayati (Biofertilizer). Prosiding Seminar Nasional "Teknologi Pemupukan dan Pemulihan Lahan Terdegradasi,Bogor 29 Juni 2012". Balai Besar Penelitian Sumber Daya Lahan Pertanian. Badan Penelitian dan Pengembangan Pertanian. Kementerian Pertanian

Soepardi, HG. (2001). Strategi usahatani agribisnis berbasis sumber daya lahan. Prosiding Seminar Nasional "Pengelolaan Sumber Daya Lahan dan Pupuk, Cisarua-Bogor 30-31 Oktober 2001". Pusat Penelitian dan Pengembangan Tanah dan Agroklimat Badan Penelitian dan Pengembangan Pertanian Departemen Pertanian.

Subagyo, H, Nata Suharta, dan Agus. B. Siswanto. (2000). Tanah-tanah pertanian di Indonesia. hlm. 21-66 dalam Buku Sumber daya Lahan Indonesia dan Pengelolaannya. Bogor: Pusat Penelitian Tanah dan Agroklimat. 